Supporting Information

\title{
Clay-Carbon Nanotubes Hybrid Materials for Nanocomposite Membranes: Advantages of Branched Structure for Proton Transport Under Low Humidity Conditions in PEMFCs
}

\author{
C. Simari ${ }^{1}$, Georgia Potsi ${ }^{2}$, Alfonso Policicchio $^{3}$, Ida Perrotta $^{4}$, I. Nicotera $^{1 *}$ \\ ${ }^{1}$ Dept. of Chemistry and Chemical Technologies, University of Calabria, Via P. Bucci 87036 Rende, Italy; \\ ${ }^{2}$ Dept. of Material Science and Engineering, University of Ioannina, GR-45110 , Ioannina , Greece; \\ ${ }^{3}$ CNISM and Dept. of Physics, University of Calabria, Via P. Bucci, 87036 Rende (CS), Italy \\ ${ }^{4}$ Dept. of Biology, Ecology and Earth Science, University of Calabria, Via P. Bucci 87036 Rende, Italy;
}

(*) isabella.nicotera@unical.it

The presence of CNTs on the clay's platelets and their oxidation/ functionalization was revealed by FT-IR spectroscopy. Figure S5 show the IR spectra of all the materials after each reaction step:

1) the spectrum of SWy mineral material presents the bands at $465 \mathrm{~cm}^{-1}$ and $1039 \mathrm{~cm}^{-1}$, which correspond to $\mathrm{Si}-\mathrm{O}$ and $\mathrm{Si}-\mathrm{O}-\mathrm{Si}$ vibrations of the clay lattice.

2) The bands in the region 1380-1400 $\mathrm{cm}^{-1}$ which appear in both the oxidized and non-oxidized samples (SWy-CNT and SWy-oxCTN), are ascribed either to carboxyl-carbonate structures or aromatic $\mathrm{C}=\mathrm{C}$ bonds.

3) the strongest prove of the nanotube's oxidation after treatment with the mixtures $\mathrm{H}_{2} \mathrm{SO}_{4} / \mathrm{HNO}_{3}$. is the appearance of the additional band at $1725 \mathrm{~cm}^{-1}$ of the $\mathrm{C}=\mathrm{O}$ stretch vibrations of carbonyl and carboxyl groups.

4) Finally, the bands in the region around $2900 \mathrm{~cm}^{-1}$ confirm the presence of the organofunctionalization being typical of $\mathrm{C}-\mathrm{H}$ stretch vibrations of the alkyl chains. 


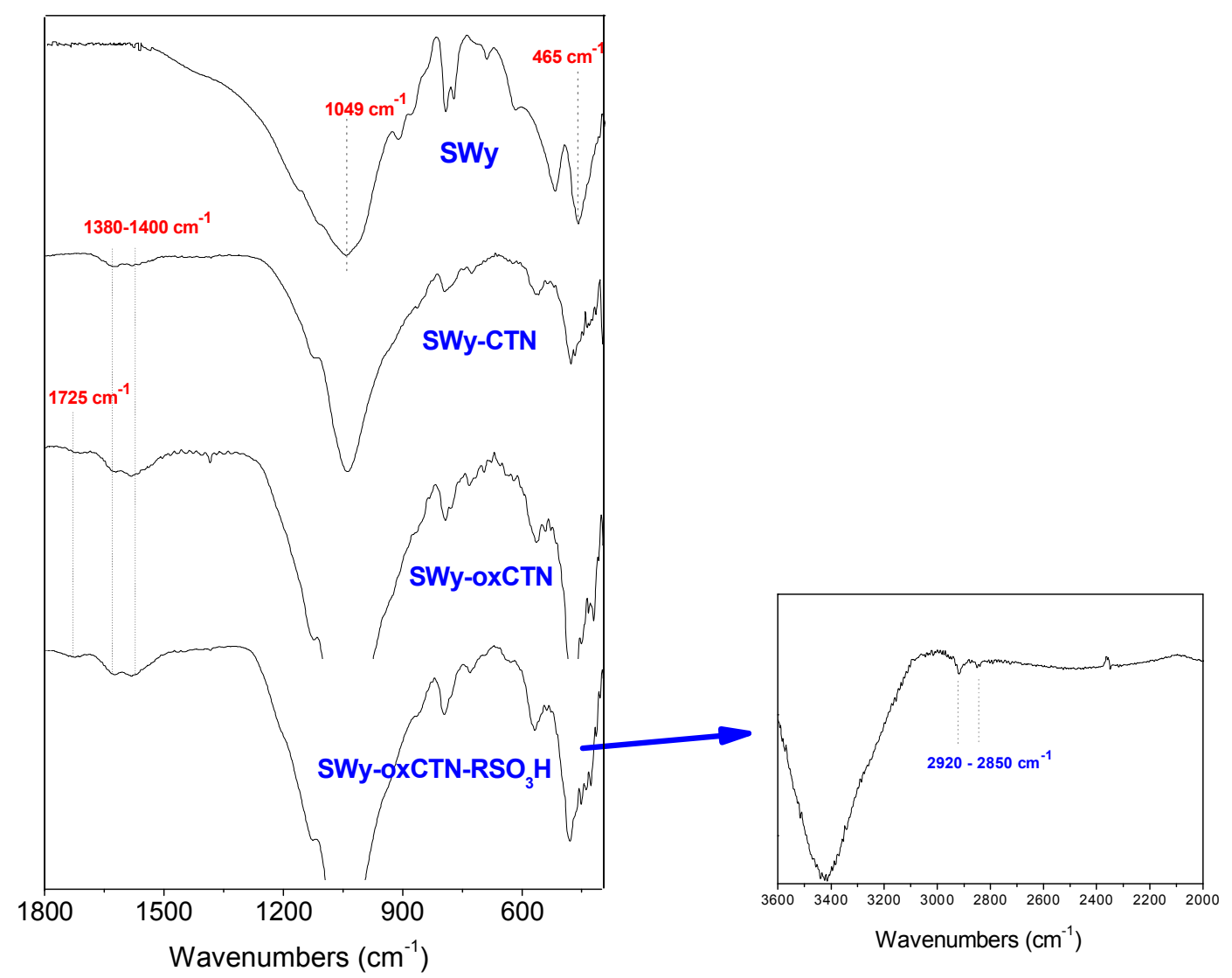

Figure S1. FT-IR spectra collected on pristine materials and final clays-CNTs nanofillers.

Raman spectroscopy is a powerful method for the characterization of the quality of the CNTs. Two characteristic CNTs peaks, at 1350 and $1595 \mathrm{~cm}^{-1}$ corresponding to graphite D- and G-bands respectively, are observed in the Raman spectra of the two SWy-CNTs synthesized materials (at $32 \%$ and $5 \%$ of yields). The G-band corresponds to the tangential stretching (E2g) mode of highly oriented pyrolytic graphite (HOPG), while the D-band originates from disorder in the $\mathrm{sp}_{2}-$ hybridized carbon atoms, characteristic for lattice distortions in the curved graphene sheets and/or tube ends. The relative intensity of the $\mathrm{D}$ and $\mathrm{G}$-bands $\left(\mathrm{I}_{\mathrm{D}} / \mathrm{I}_{\mathrm{G}}\right)$ reveals the degree of disorder in the graphite sheets and it can be used as a measure of the crystallinity of the synthesized CNTs. ${ }^{1}$

Before the oxidation reaction, the $\mathrm{I}_{\mathrm{D}} / \mathrm{I}_{\mathrm{G}}$ value is 0.79 , that increases up to 0.86 after oxidation. These values are lower than those reported (ID/IG $=0.85-1.3)$ in the literature and suggest high graphitization degree and thus good quality of the graphitic structures. ${ }^{2-3}$ 


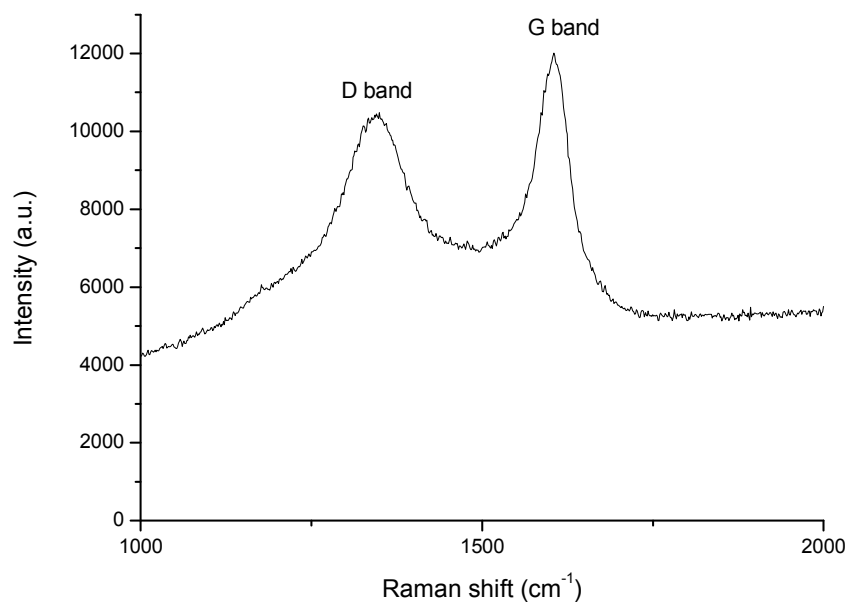

Figure S2. Characteristic Raman spectra of CNTs grown at $700{ }^{\circ} \mathrm{C}$ over Fe-Ni catalyst on SWy-clay's surface.
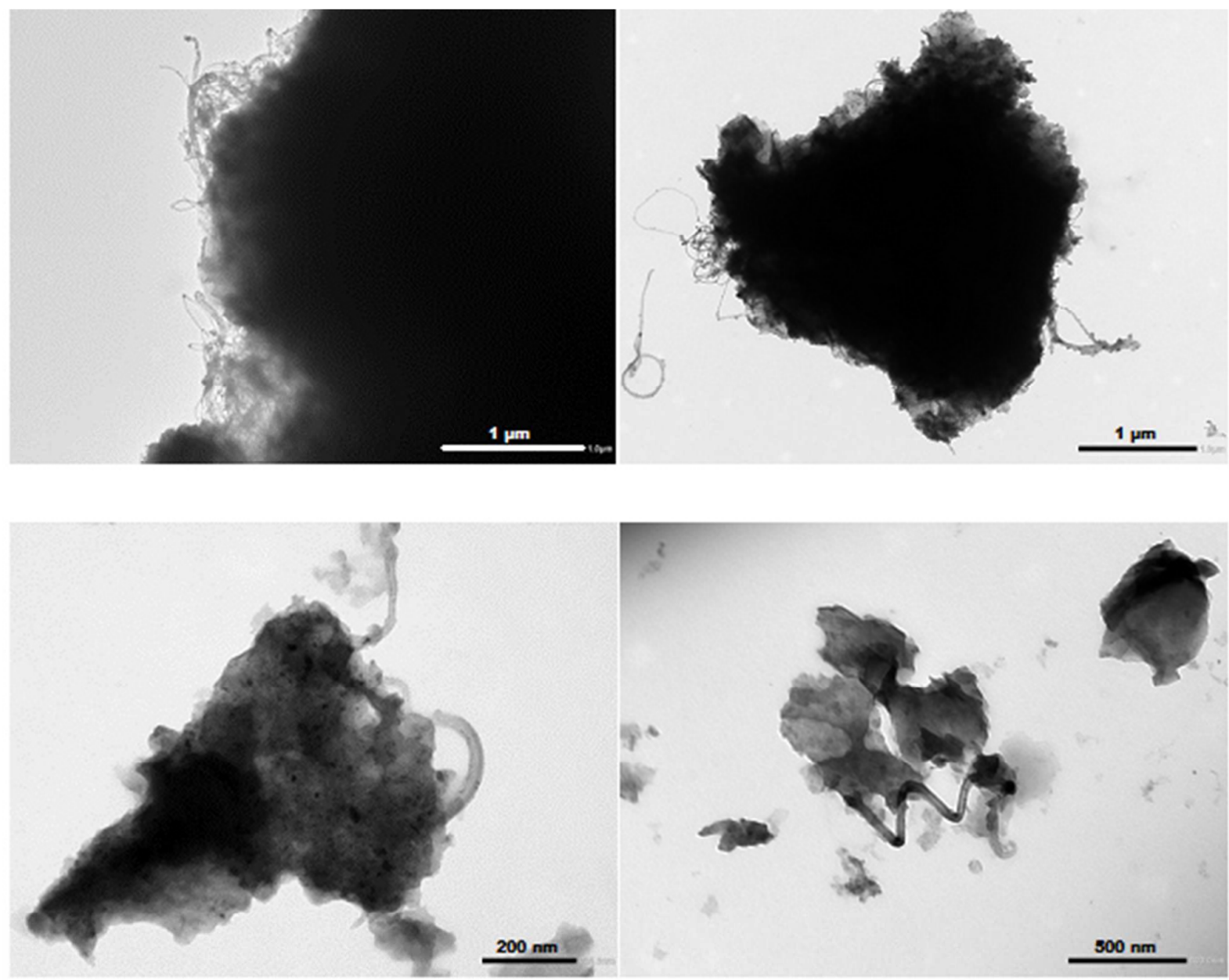

Figure S3. TEM images of the products $\mathrm{SWy}-\mathrm{oxCNTs}-\mathrm{RSO}_{3} \mathrm{H}$ at $32 \%$ (first row) and 5\% (second row) of yields, respectively. 

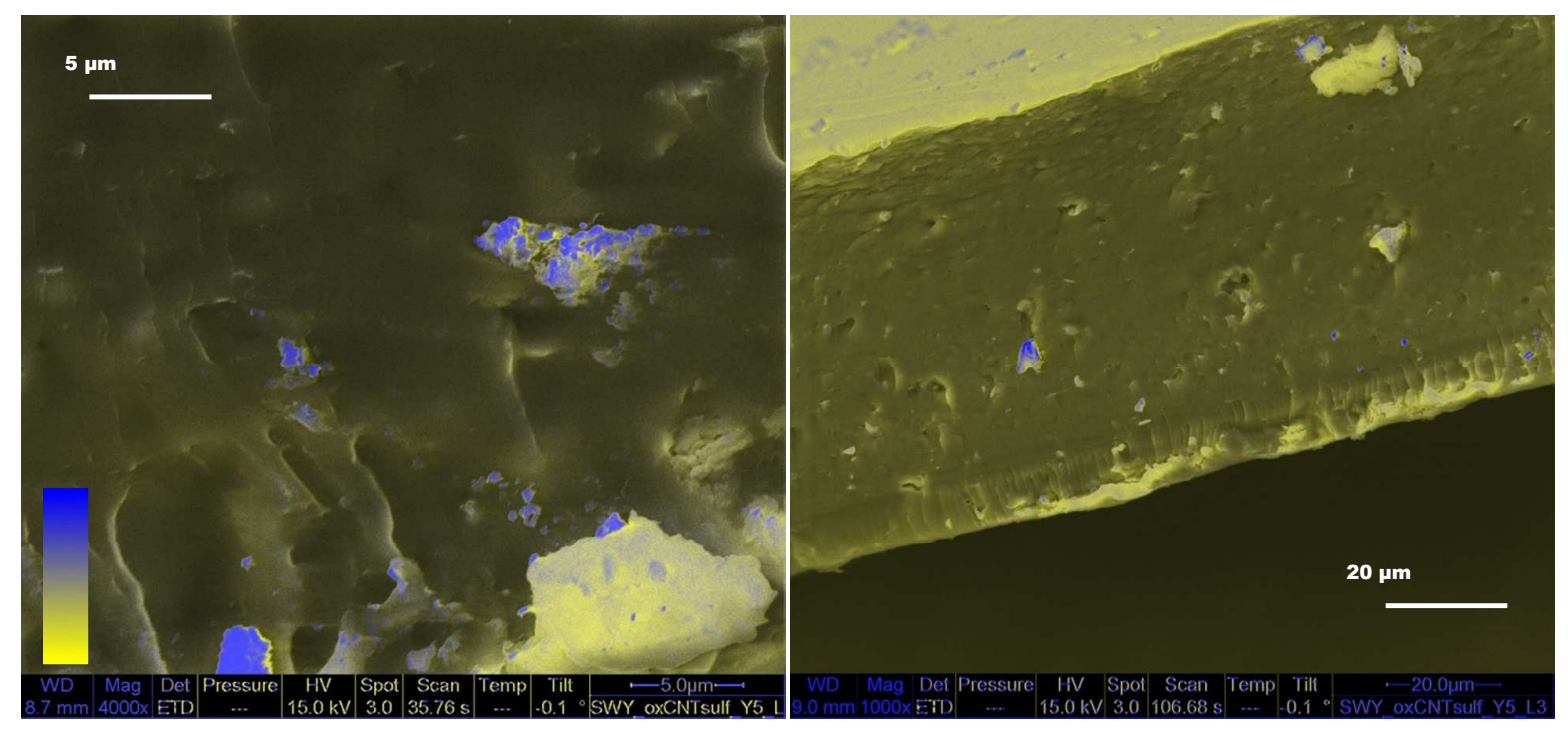

Figure S4. SEM-BSE images of representative composites membranes, N/SWy-oxCNTs-RSO3H(y5) and $\mathrm{N} / \mathrm{SWy}$-oxCNTs (y5), in false colors to put in evidence the clays clusters distribution. The yellow-to-blue color bar spans from the lowest BSE intensity to the highest one.

The results obtained show that the composite N/SWy-oxCNTs- $\mathrm{SO}_{3} \mathrm{H}(\mathrm{y} 5)$ is certainly the most promising. For this nano-additive, the effect of the loading with respect to the polymer, was investigated. Accordingly, composite membranes to $2 \mathrm{wt} \%$ and $3 \mathrm{wt} \%$ were prepared and analyzed, while, higher loading lead to inhomogeneous membranes, and therefore were not taken into account. In Figure S4, the diffusion coefficients vs. temperature is shown. De facto there is not a significant difference between the three loadings; the $2 \mathrm{wt} \%$ may be the best compromise, because it increases the water uptake from 31-32 wt $\%$ (in the loadings 1 and $3 \mathrm{wt} \%$, respectively) at $37 \mathrm{wt} \%$. 


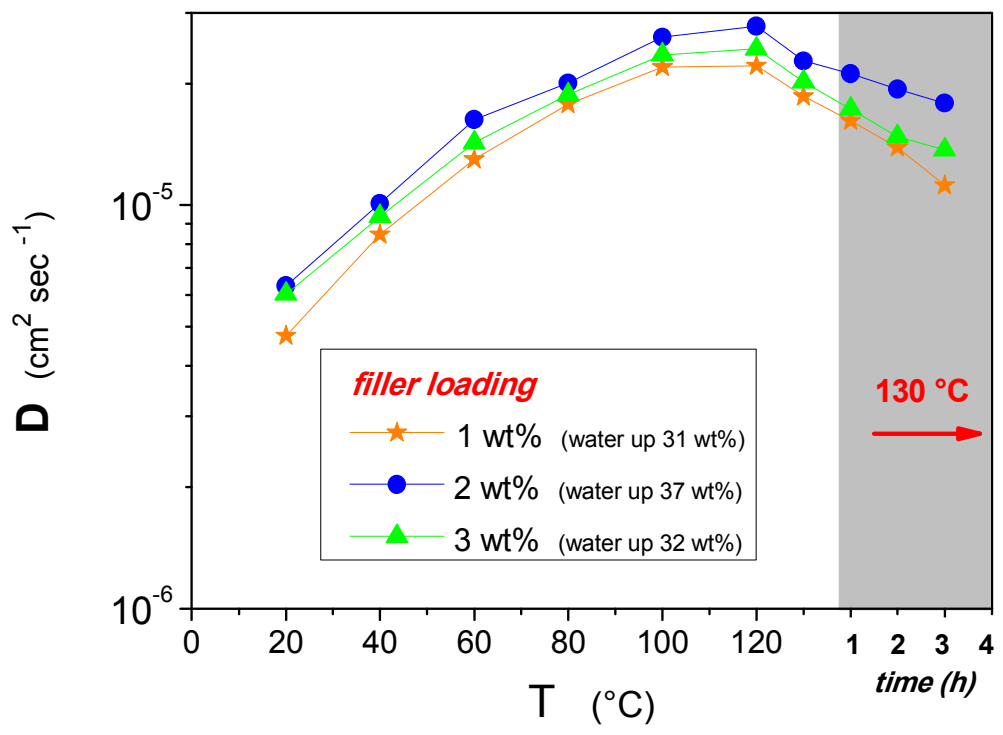

Figure S5: Self-diffusion coefficients as function of the temperature (from $20^{\circ} \mathrm{C}$ up to $130{ }^{\circ} \mathrm{C}$ ) of the water confined in N/SWy-oxCNTs-SO3H(y5) composites membranes at different filler to polymer loading. In the graph are also plotted the data collected at $130^{\circ} \mathrm{C}$ after several hours.

\section{References}

(1) Tsoufis, T.; Xidas, P.; Jankovic, L.; Gournis, D.; Saranti, A.; Bakas, T.; Karakassides, M. A. Catalytic Production of Carbon Nanotubes Over Fe-Ni Bimetallic Catalysts Supported on MgO. Diam. Relat. Mater. 2007, 16, 155-160.

(2) Xu, Z.; Wang, H.; Hwang, J.-Y. Complex Carbon Nanotube Superstructures Synthesized with Natural Mineral Catalysts. Carbon 2007, 45, 873-879.

(3) Georgakilas, V.; Gournis, D.; Karakassides, M. A.; Bakandritsos, A.; Petridis, D. Organic Derivatization of Single-Walled Carbon Nanotubes by Clays and Intercalated Derivatives. Carbon 2004, 42, 865-870.

(13) Adjemian, K. T.; Dominey, R.; Krishnan, L.; Ota, H.; Majsztrik, P.; Zhang, T.; Mann, J.; Kirby, B.; Gatto, L.; Velo-Simpson, M.; Leahy, J.; Srinivasan, S.; Benziger, J. B.; Bocarsly, A. B. Function and Characterization of Metal Oxide-Nafion Composite Membranes for Elevated-Temperature $\mathrm{H}_{2} / \mathrm{O}_{2}$ PEM Fuel Cells. Chem. Mater. 2006, 18, 2238-2248. 